\title{
Improving TRIZ 40 Inventive Principles Grouping in Redesign Service Approaches
}

\author{
Nadhmi Gazem ${ }^{1} \&$ Azizah Abdul Rahman ${ }^{1}$ \\ ${ }^{1}$ Faculty of Computing, Universiti Teknologi Malaysia, Skudai, Johor, Malaysia \\ Correspondence: Nadhmi Gazem, Faculty of Computing, Universiti Teknologi Malaysia, 81310, Skudai, Johor, \\ Malaysia. Tel: 60-17-242-1838. E-mail: nadhmigazem@gmail.com
}

Received: June 3, 2013 Accepted: July 7, 2014 Online Published: August 20, 2014

doi:10.5539/ass.v10n17p127 URL: http://dx.doi.org/10.5539/ass.v10n17p127

\begin{abstract}
Over the past decade, different studies have been conducted in order to create or redesign services by using the systematic innovation method known as TRIZ - the theory of inventive problem solving. TRIZ has a range of powerful tools to solve problems and the most widely tool used to identify and solve contradictions in the system are the 40 inventive principles (IPs). Only a few studies have grouped the 40 IPs in terms of service context to overcome the problem of consuming time and effort while the designer endeavors to find the best principle(s) that may help to solve a service problem. This study enhanced and refined the previous grouping of the 40 IPs under five service redesign approaches (SRA): self-service, direct service, pre-service, bundled service and physical service. The methodology used to group these principles was by mapping between the principles hints, which have been developed to interpret the TRIZ principles in service context, and each characteristic of the SRA. A comparison between TRIZ contradiction matrix and proposed grouping for a problem case study has been conducted, and it has demonstrated and verified the feasibility of grouping of the 40 principles according to the SRA.
\end{abstract}

Keywords: redesign service approach, systematic innovation, TRIZ, physical contradiction, engineering contradiction, 40 inventive principles

\section{Introduction}

Systematic innovation method such as TRIZ provides problem solvers with different solutions that can generate effective and innovative solutions with low cost. Even though the TRIZ was designed for use in technical areas, current studies are focusing on using TRIZ in non-technical sectors such as the service sector (Chai, Zhang, \& Tan, 2005; Chen, Shie, Wang, \& Yu, 2012; Lin \& Su, 2007; Mann \& Domb, 1999; Regazzoni, Pezzotta, Persico, Cavalieri, \& Rizzi, 2012; Retseptor, 2003; Ruchti \& Livotov, 2001). Mann et al. (1999) indicated that the power of TRIZ is in its ability to eliminate contradictions rather than using the conventional methods, such as compromises or trade-offs. Among many different tool sets of TRIZ, the 40 inventive principles (IPs) are the most important and frequently used for eliminating contradiction problems (Cong \& Tong, 2008; Lin et al., 2007). Each IP consists of sub-principles, which expand the various views for each principle. In fact, solving contradiction problems usually produces innovative solutions (Hsia \& $\mathrm{Pu}, 2013$ ).

In order to simplify using the 40 IPs, TRIZ offers a contradiction matrix consisting of 39 parameters such as weight, length, shape, strength, etc. This matrix is associated with engineering contradiction problem. It helps a problem solver to overcome the conflict of 39 parameters in technological systems. The 39 parameters are arranged in a two-dimensional matrix. Down the rows represents improving parameters, and across the columns represents worsening parameters. Each intersection in the matrix refers to corresponding IPs that can be used to resolve the contradiction between these parameters (Chen et al., 2012; Xie, Tang, \& Shao, 2012).

TRIZ contradiction matrix has been used in non- technical context as well. Mann (2007) developed contradiction matrix for business and management context. The matrix involved 31 parameters that can be generally found in managing the business. Furthermore, Chen et al. (2012) developed the service-quality parameters for ageing-in-place service in health sector, and mapped between them and TRIZ parameters. In addition, Mann (2007) developed contradiction matrix for business and management context. However, this matrix can be used only in contradiction between two parameters. 
In general, the contradiction between two parameters is known as the Engineering Contradiction (EC) in TRIZ. For example, improving one parameter such as reducing the weight of a table could cause the worsening of another table parameter such as strength. The other type of contradiction is called Physical Contradiction (PC), which works with single parameter contradiction. This contradiction shows the conflicting values of one parameter. For instance, a light in a classroom should be strong, but at the same time light should be low to save power. The PC strategy is more focused and provides better inventive solutions (San, 2009). Both contradiction types (EC and PC) basically use 40 IPs to solve any contradiction in a system.

In order to facilitate using 40 IPs in services context with PC strategy, previous study by (Gazem \& Rahman, 2013) grouped IPs with five typical service redesign approaches (SRA). The grouping method was based on mapping between the sub-principles and their examples with SRA' characteristics. Thus, IPs can be scoped according to the type of service that needs to be redesigned to eliminate the contradiction problem. This study is to refine and enhance pervious grouping of the 40 IP based on an in-depth understanding of each principle using the recent TRIZ interpretation in service context developed by N. Gazem and Rahman (2014). Thus the grouping can be more precise and accurate.

The remainder of this paper is divided into five sections. The second section described the related works in SRA, implementing IPs in the service sector, and classifying the IPs. The third section illustrated the methodology used in this study for grouping IPs with SRA. The fourth section discussed grouping results. The fifth section illustrated the usefulness of the proposed grouping using a case study approach, and the sixth section provided conclusions and directions for future research.

\section{Related Work}

\subsection{TRIZ with Design Service}

TRIZ was developed by Genrich Altshuller and his colleagues in the former Union of Soviet Socialist Republics (USSR) in 1946. TRIZ is one of the most famous systematic innovation methods, providing a set of tools and techniques that can be applied within a framework to both business development and technical product development, and in a manner that can be understood by the non-specialist innovator. TRIZ gives problem solvers different tools, and the most common tool used for the elimination of contradiction problems is the 40 IPs (Cong et al., 2008; Lin et al., 2007). Filippi, Motyl, and Ciappina (2011) classified the 40 IPs as an appropriate tool to design or redesign solutions. IPs provide a problem solver with a full solution thinking description with examples of how other problem solvers have used a particular principle to overcome a conflict in a system. Cong et al. (2008) classified the 40 IPs with text similarity and with meaning similarity into 22 classes to facilitate building an expert automatic patent classification system for TRIZ users in the technical context. For instance, principle "\#13: The other way round (Inversion), sub-principle (b): Make object a moving part, or make a non-moving part movable and the outside environment immovable", and principle "\#15: Dynamization, sub-principle (c): If an object is immovable, make it movable or interchangeable". Both principles are about changing the way an objective works.

Because TRIZ was mainly developed in the engineering field, many of its principles and tools were originally designed to provide innovative solutions to technical problems. However, the trend now is to use TRIZ to resolve non-technical problems such as those found in the service sector. Efforts to implement TRIZ in a service context are normal due to the fact that innovation is critical to ensure crucial for ensuring continuous growth of service sectors (Kuo, Chi, \& Yeh, 2013). Generally, the classical method in TRIZ to create or solve problems in a service context has three stages: define the problem, generate solutions, and evaluate solutions. The solution generation stage provides the solver with a variety of tools, such as technical contradictions/inventive principles, physical contradictions, Su-Field analysis, ideal final result, resources, etc., in order to resolve a given problem. In this context, different studies have used many of these tools to help the solver find solutions to service system contradictions. A study conducted by Zhang, Chai, and Tan (2003) interpreted 40 inventive principles with examples drawn from service operations management. Chai et al. (2005) developed a model for creating new service based on TRIZ which used the 40 IPs for predicting problem solutions based on two case studies. Lin et al. (2007) pointed out that 39 parameters formed a contradiction matrix and the 40 IPs can be used in the service sector for identifying the solutions. Kim and Park (2012) recommended adopting a model for linking service decision factors and the 40 IPs were modified for the service industry by 'Zhang' - see (Kim et al., 2012)- in their study to generate solutions. In addition Chen et al. (2012) proposed a service innovation model for ageing-in-place. They developed service-quality parameters for ageing-in-place and integrated them with TRIZ contradiction parameters to deal with service contradiction. 
The method of interpreting the 40 principles to solve a contradiction in the technical context is relatively more tangible and easier to realize, unlike service which is intangible and abstract (Zhang, Chai, \& Tan, 2005). For instance, sub-principle (a) in principle \#7-Nested doll: "One object is placed inside another. That object is placed inside a third one, and so on". Altshuller, Shulyak, and Rodman (2005) provided a very realizable example, such as "measuring cups". However, applying this principle in the service context may give intangible and abstract solutions such as "flight travelling would be a boring experience if no more extra services like entertainment are incorporated in the flight package", (Zhang et al., 2003). In addition, the sub-principles of the 40 IPs in the technical aspect can mean obvious change in performance or function if they are implemented on an object, while some sub-principles may mean nothing in the case of service. This is because technical products are tangible, and any change in that object will be clearly noticed and easily measured. In contrast, a service product is intangible, thus the sub-principle may not be applicable.

In addition, the interpretation of the TRIZ inventive principles in the service context varies from one author to another (Cong et al., 2008; Dourson, 2004; N. Gazem et al., 2014; Mann et al., 1999). This is because the interpretation depends on empirical experience, the opinion of the author, or examples from others studies, and the most important thing is the lack of study of service patents. Moreover, particular principles from the 40 IPs in the service context may have different usage. Taking principle \#15-Dynamization as an example where the service is divided into parts so each part can work according to different situations (e.g. companies increase the working hours by separating the employees' shift from one to two shifts per day during peak seasons). In another perspective, Dynamization principle can be seen as grouping services (e.g., adding temporary sell offers during peak seasons).

\subsection{Redesign Service Approaches}

The process of redesigning a service may lead to the innovation of new services. Study conducted by Metters, Pullman, and King-Metters (2003) pointed out that designing a service system for developing new services has thirteen factors that should be take into consideration by the designer. However, the innovation option in services is not only formed when developing new services; it can also be achieved from redesigning services (L.Berry \& Lampo, 2000). L.Berry et al. (2000) also mentioned that existing service processes must be analysed, outdated assumptions eliminated, and customer perspectives adopted to revitalize existing services. They categorized the process of redesign services into five typical approaches after analysing many examples in redesign services as shown in Figure 1. Although L.Berry et al. (2000) suggested that more research on addressing the redesign service approaches be conducted, the five approaches have not been updated yet.

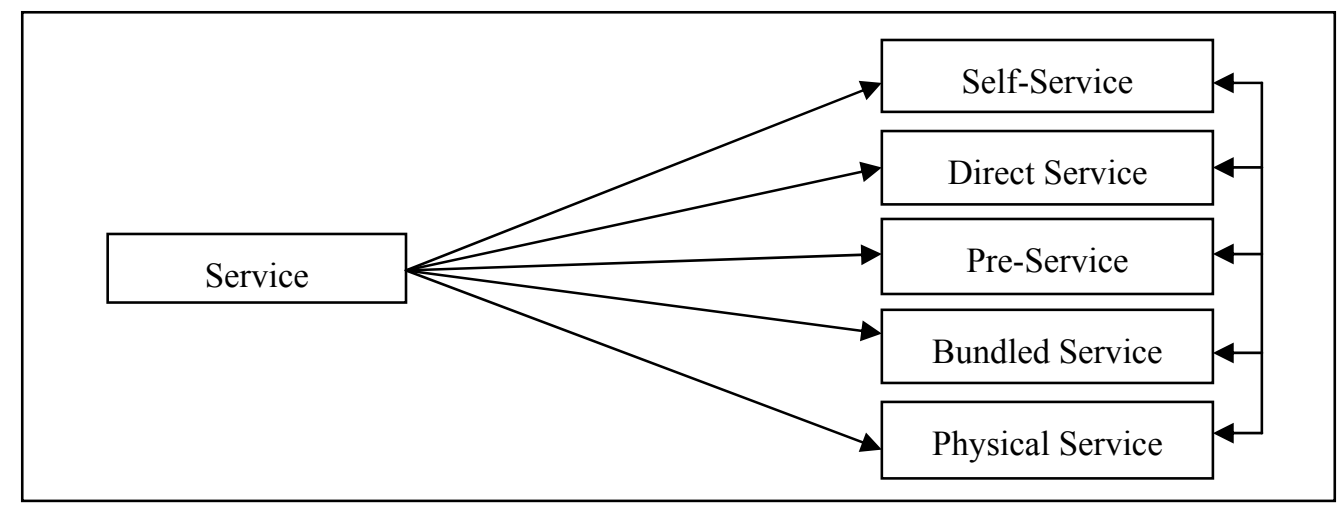

Figure 1. Service redesign approaches: Source from (Berry et al., 2000)

In each SRA, L.Berry et al. (2000) developed a set of characteristics which are used to place a service example according to the strongest fit. These characteristics clearly present different service delivery situations that require redesigning current services using a specific approach. According to their study, it was obvious that innovation from different service industries could provide the same basic solutions. This concept is the same with the TRIZ hypothesis which indicates that there are universal principles of invention that are the basis for creative innovation in manufactory industries, and if these principles could be identified and codified, they could be taught to people to make the process of invention more predictable. Thus, identifying patterns by collecting as many examples as possible from the service industry may prove that innovative services could have their own principles just like the TRIZ 40 IPs (Zhang et al., 2003). 


\section{A New Grouping Method}

The different studies and methods that have been mentioned in the literature review for utilizing IPs illustrate the importance of reducing time consuming processes during the use of such tools to resolve contradiction problems, or even in facilitating automatic patent classification. Therefore, this study attempted to achieve the same goal.

Previous study by N. A. J. Gazem et al. (2013) grouped the 40 IPs under the five service redesign approaches. The grouping methodology was based on text similarity and meaning similarity. Text similarity was the first stage of categorisation and it focused on similarity between the inventive principles with each SRA identity. For instance, the self-service approach has similarity in text information with principle \#25-self-service. Both indicate the operating of the service by users. Thus this principle can be grouped under this service approach. The second stage included two methods. The first method looked for meaning similarity between the sub-principles information and each characteristic. For example, sub-principle (a) in \#5: Merging (Consolidation): "Bring closer together or merge identical or similar objects, assemble identical or similar parts to perform parallel operations", and bundled service characteristic: "Customers can be segmented based on use or need". The sub-principle (a) and bundled service characteristic indicate the bundling of services for a particular group of people in order to fulfil their needs. The second method was based on variant service examples, which have been used or could be used with the 40 IPs. For instance, the meaning similarity between the example of principle \#21-Skipping: "To increase the automation level, many service organizations try to shorten the direct customer contact time (e.g., the use of automated phone answering systems or online reservation system), (Zhang et al., 2003)", and the self-service characteristic: "Speed of service delivery is paramount". The example in sub-principle "Skipping" and self-service characteristic indicates the need to increase the speed of service delivery to customers.

The previous method depended more on meaning similarity of variant service examples. Most of the examples that have been used by N. A. J. Gazem et al. (2013) depend on collecting different examples from (Fox, 2008; L.Berry et al., 2000; Mann, 2007; Zhang et al., 2003). Therefore, a limited number of examples controlled the grouping process rather than depending on the real understanding of the principles. Moreover, depending on examples is not a solid method for grouping because different principles could use the same example. For instance, principles “\#26-Copying" and "\#35-Parameter Changes (Transformation of Properties)" use the same example: numerical simulation, (Mann, 2007). The new grouping in this study avoided previous deficiencies through an in-depth understanding of each principle by using the recent 40 IPs interpretations, which were developed by (Gazem et al., 2014), for service context.

Table 1. Grouping TRIZ principles with the self-service approach characteristic

\begin{tabular}{|c|c|c|}
\hline Characteristics & TRIZ principles & Hints with example \\
\hline \multirow{7}{*}{$\begin{array}{l}\text { B. Speed of } \\
\text { service } \\
\text { delivery is } \\
\text { paramount. }\end{array}$} & 1: Segmentation & $\begin{array}{l}\text { b) Break down the services process into small process or increase the degree } \\
\text { of fragmentation or segmentation of the service process. }\end{array}$ \\
\hline & & - Supermarkets provide express chaser to expedite the payment process. \\
\hline & 2: Extraction & $\begin{array}{l}\text { c) Change the service operation to self-service. } \\
\text { - Train stations set up automated ticket machines. }\end{array}$ \\
\hline & $\begin{array}{l}\text { 10:Preliminary } \\
\text { action (Prior }\end{array}$ & $\begin{array}{l}\text { d) If the customer requires the service immediately, the service process } \\
\text { should be simplified to improve its efficiency. }\end{array}$ \\
\hline & Action) & - New students can fill their information and submit their documents online. \\
\hline & 21: Skipping & $\begin{array}{l}\text { a) Shorten the waiting time for a service. } \\
\text { - Automated answering service allows customers skipping front-line } \\
\text { employee assistance and communicates with the desired person or } \\
\text { department directly. }\end{array}$ \\
\hline & 25: Self-service & $\begin{array}{l}\text { b) Determine which part of the service is most affected by delivery speed. } \\
\text { Then find a way to convert that process to a self-service method. } \\
\text { - In fast-food, customers can act as partial employee, where they can serve } \\
\text { themselves by assemble the meals for their preferences. }\end{array}$ \\
\hline
\end{tabular}

The new 40 IPs interpretation includes a comprehensive introduction of each principle that gives a good understanding for a problem solver. In addition, each principle has a set of hints that give the problem solver different suggestions for using a specific principle. In addition, these hints provide a more practical explanation of each principle. Therefore, using these hints for mapping between the 40 IPs with the service approaches will be a good method for improving the grouping process. For example, according to N. Gazem et al. (2014) the hint 
(a) in the principle \#21-Skipping: "shortening the waiting time during performing the service" can be mapped with the characteristic: "Speed of service delivery is paramount" in self-service approach. Consequently, the principle "Skipping" can be grouped under this characteristic. Table 1 shows a snapshot of grouping some 40 IPs with one of self-service characteristic.

In Table 1, the authors also provided one example with each principle's hint. This step was to illustrate the logical mapping between principle and service approach characteristics.

\section{Results and Discussion}

The new method of grouping 40 IPs with the SRA improved the grouping tables and added more principles for each SRA characteristic. Taking the Table 1 results and comparing them with the previous study result shows that current self-service characteristic "customer require frequent and flexible access" includes 4 principles instead of 2 . Tables 2,3,4,5 \& 6 show the results of the new grouping process.

Table 2. Inventive principles with self-service approach characteristics

\begin{tabular}{|c|c|}
\hline Characteristics & TRIZ principles \\
\hline A. Customers require frequent and flexible access. & $\begin{array}{l}\text { 2: Extraction } \\
\text { 17: Resonance } \\
\text { 20: Continuity of useful action } \\
\text { 31: Holes }\end{array}$ \\
\hline B. Speed of service delivery is paramount. & $\begin{array}{l}\text { 1: Segmentation } \\
\text { 2: Extraction } \\
\text { 10: Prior Action } \\
\text { 21: Skipping } \\
\text { 25: Self-service }\end{array}$ \\
\hline $\begin{array}{l}\text { C. Service performance requires limited skills that are } \\
\text { easily transferable to customers. }\end{array}$ & $\begin{array}{l}\text { 25: Self-service } \\
\text { 38: Enriched Atmosphere }\end{array}$ \\
\hline $\begin{array}{l}\text { D. Technology exists to enable customers to perform the } \\
\text { service. }\end{array}$ & $\begin{array}{l}\text { 2: Extraction } \\
\text { 7: Nesting } \\
\text { 13: Inversion } \\
\text { 15: Dynamization } \\
\text { 17: Resonance } \\
\text { 21: Skipping } \\
\text { 24: Intermediary } \\
\text { 25: Self-service } \\
\text { 35: Transformation of Properties }\end{array}$ \\
\hline $\begin{array}{l}\text { E. Customers may be concerned about disclosing private } \\
\text { information to service personnel. }\end{array}$ & $\begin{array}{l}\text { 2: Extraction } \\
\text { 13: Inversion } \\
\text { 21: Skipping } \\
\text { 24: Intermediary } \\
\text { 25: Self-service } \\
\text { 30: Thin and Flexible } \\
\text { 39: Calm Atmosphere }\end{array}$ \\
\hline $\begin{array}{l}\text { F. Gross margins are low, making cost-saving alternative } \\
\text { especially attractive. }\end{array}$ & $\begin{array}{l}\text { 2: Extraction } \\
\text { 4: Symmetry Change } \\
\text { 5: Consolidation } \\
\text { 8: Counter Balance } \\
\text { 25: Self-service } \\
\text { 35: Transformation of Properties }\end{array}$ \\
\hline
\end{tabular}

Table 3. Inventive principles with direct service approach characteristics

\begin{tabular}{ll}
\hline Characteristics & TRIZ principles \\
\hline A. Customers must significantly disrupt their normal & 1: Segmentation \\
routines to receive the service. & 2: Extraction \\
& 3: Optimal Resource \\
& 12: Remove Tension \\
\hline
\end{tabular}




\begin{tabular}{ll}
\hline & $13:$ Inversion \\
& $15:$ Dynamization \\
& 37 : Relative Change \\
\hline B. Customers' inconvenience in visiting the service facility & $2:$ Extraction \\
outweighs the benefits of their service. & $12:$ Remove Tension \\
& $13:$ Inversion \\
& $22:$ Convert harm into benefit \\
& $24:$ Intermediary \\
& $35:$ Transformation of Properties \\
\hline C. Customers dislike personally interacting with the service & $2:$ Extraction \\
provider. & $4:$ Symmetry Change \\
& $13:$ Inversion \\
& $14:$ Curvature \\
& $21:$ Skipping \\
& $24:$ Intermediary \\
& $25:$ Self-service \\
& $30:$ Thin and Flexible \\
& $4:$ Symmetry Change \\
& $7:$ Nesting \\
& $11:$ Beforehand Cushioning \\
D. Technology allows the remote delivery of services. & $13:$ Inversion \\
& $20:$ Continuity of useful action \\
$24:$ Intermediary \\
$26:$ Copying \\
$31:$ Holes \\
$35:$ Transformation of Properties \\
\hline
\end{tabular}

Table 4. Inventive principles with pre-service approach characteristics

\begin{tabular}{|c|c|}
\hline Characteristics & TRIZ principle \\
\hline $\begin{array}{l}\text { A. Customers must supply detailed information to receive } \\
\text { the service. }\end{array}$ & $\begin{array}{l}\text { 1: Segmentation } \\
\text { 10: Prior Action } \\
\text { 23: Feedback } \\
\text { 31: Holes } \\
\text { 34: Rejecting and Regenerating Parts }\end{array}$ \\
\hline B. Customers are usually in a hurry to receive the service. & $\begin{array}{l}\text { 1: Segmentation } \\
\text { 2: Extraction } \\
\text { 10: Prior Action } \\
\text { 13: Inversion } \\
\text { 20: Continuity of useful action } \\
\text { 21: Skipping } \\
\text { 25: Self-service } \\
\text { 31: Holes }\end{array}$ \\
\hline C. Customers plan service consumption ahead of time. & $\begin{array}{l}\text { 3: Optimal Resource } \\
\text { 9: Prior Counteraction } \\
\text { 10: Prior Action } \\
\text { 15: Dynamization } \\
\text { 18: Mechanical vibration } \\
\text { 19: Periodic action } \\
\text { 22: Convert harm into benefit } \\
\text { 23: Feedback } \\
\text { 27: Cheap Disposables } \\
\text { 36: Phase Transitions (Phenomenon Utilization) }\end{array}$ \\
\hline D. Customers use the service frequently. & $\begin{array}{l}\text { 9: Prior Counteraction } \\
\text { 20: Continuity of Useful Action } \\
\text { 21: Skipping }\end{array}$ \\
\hline
\end{tabular}


Table 5. Inventive principles with bundled service characteristics

\begin{tabular}{|c|c|}
\hline Characteristics & TRIZ principle \\
\hline \multirow[t]{8}{*}{ A. Customers can be segmented based on use or need. } & 1: Segmentation \\
\hline & 4: Symmetry Change \\
\hline & 5: Consolidation \\
\hline & 17: Resonance \\
\hline & 23: Feedback \\
\hline & 32: Change the Color \\
\hline & 35: Transformation of Properties \\
\hline & 40: Composite materials (Non Homogeneity) \\
\hline \multirow[t]{3}{*}{ B. Efficient consumption requires technical knowledge. } & 6: Multi-functionality \\
\hline & 8: Counter Balance \\
\hline & 34: Rejecting and Regenerating Parts \\
\hline \multirow{11}{*}{$\begin{array}{l}\text { C. Customers associate core service with other related } \\
\text { services. }\end{array}$} & 3: Optimal Resource \\
\hline & 4: Symmetry Change \\
\hline & 5: Consolidation \\
\hline & 6: Multi-functionality \\
\hline & 7: Nesting \\
\hline & 16: Slight Less/Slightly More \\
\hline & 20: Continuity of useful action \\
\hline & 24: Intermediary \\
\hline & 31: Holes \\
\hline & 33: Homogeneity \\
\hline & 38: Enriched Atmosphere \\
\hline \multirow[t]{13}{*}{ D. Customers are convenience minded. } & 3: Optimal Resource \\
\hline & 4: Symmetry Change \\
\hline & 5: Consolidation \\
\hline & 6: Multi-functionality \\
\hline & 7: Nesting \\
\hline & 8: Counter Balance \\
\hline & 11: Beforehand Cushioning \\
\hline & 19: Periodic action \\
\hline & 26: Copying \\
\hline & 27: Cheap Disposables \\
\hline & 29: Intangibility \\
\hline & 33: Homogeneity \\
\hline & 38: Enriched Atmosphere \\
\hline
\end{tabular}

Table 6. Inventive principles with physical service characteristics

\begin{tabular}{ll}
\hline Characteristics & TRIZ principle \\
\hline A. Consumption requires the customer's presence at the & 3: Optimal Resource \\
service facility. & 15: Dynamization \\
& 22: Convert harm into benefit \\
& 28: Another Sense \\
& 35: Transformation of Properties \\
\hline B. The service is difficult for customers to evaluate prior to & 3: Optimal Resource \\
purchase. & 7: Nesting \\
& 17: Resonance \\
& 23: Feedback \\
& 27: Cheap Disposables \\
& 34: Rejecting and Regenerating Parts \\
\hline C. Physical comfort is an important determinant of customer & 3: Optimal Resource \\
and/or employee satisfaction. & 5: Consolidation \\
& 6: Multi-functionality \\
& 14: Curvature \\
\hline
\end{tabular}




\begin{tabular}{ll}
\hline & $28:$ Another Sense \\
& 32: Change the Color \\
& 39: Calm Atmosphere \\
\hline D. Competing service are quite similar to one another in & 4: Symmetry Change \\
operational performance. & 6 : Multi-functionality \\
& $13:$ Inversion \\
& $16:$ Slight Less/Slightly More \\
& 17: Resonance \\
& $26:$ Copying \\
& $40:$ Composite materials (Non Homogeneity) \\
\hline
\end{tabular}

Table 7. A priority of principles with the service redesign approaches

\begin{tabular}{|c|c|c|}
\hline Approach & TRIZ principles & Repetition \\
\hline \multirow{7}{*}{ Self-service } & 2: Extraction & 5 \\
\hline & 25:Self-service & 5 \\
\hline & 21: Skipping & 3 \\
\hline & 13: Inversion & 2 \\
\hline & 17: Resonance & 2 \\
\hline & 24: Intermediary & 2 \\
\hline & 35: Transformation of Properties & 2 \\
\hline \multirow[t]{6}{*}{ Direct service } & 13: Inversion & 4 \\
\hline & 2: Extraction & 3 \\
\hline & 24: Intermediary & 3 \\
\hline & 4: Symmetry Change & 2 \\
\hline & 12: Remove Tension & 2 \\
\hline & 35: Transformation of Properties & 2 \\
\hline \multirow[t]{7}{*}{ Pre-service } & 10: Prior Action & 3 \\
\hline & 1: Segmentation & 2 \\
\hline & 9: Prior Counteraction & 2 \\
\hline & 20: Continuity of useful action & 2 \\
\hline & 21: Skipping & 2 \\
\hline & 23: Feedback & 2 \\
\hline & 31: Holes & 2 \\
\hline \multirow[t]{8}{*}{ Bundled service } & 4: Symmetry Change & 3 \\
\hline & 5: Consolidation & 3 \\
\hline & 6: Multi-functionality & 3 \\
\hline & 3: Optimal Resource & 2 \\
\hline & $7:$ Nesting & 2 \\
\hline & 8: Counter Balance & 2 \\
\hline & 33: Homogeneity & 2 \\
\hline & 38: Enriched Atmosphere & 2 \\
\hline \multirow[t]{4}{*}{ Physical service } & 3: Optimal Resource & 3 \\
\hline & 6: Multi-functionality & 2 \\
\hline & 17: Resonance & 2 \\
\hline & 28: Another Sense & 2 \\
\hline
\end{tabular}

According to the new understanding of the principles interpretation, the authors found that some principles which were grouped previously by (Gazem et al., 2013), showed weak relation with some characteristics. Therefore, the authors eliminated those principles. For instance, characteristic D: "Customers use the service frequently" in pre-service approach included principle "\#19-Periodic action" in proviruses grouping. This principle has weak correlation with that characteristic. According to N. Gazem et al. (2014) this principle refers to think of opposite continuity. Therefore, the authors eliminated this principle since this characteristic (D) refers to making service work continually. 
Moreover, Tables 2- 6 showed that some of the 40 IPs can be grouped with a service approach more than once, but within different service approach characteristics. For instance, principle "\#2-Extraction" was grouped three times with direct service approach in Table 3. This is because the hints associated with this principle can be used in different characteristics of Direct Service Approach. For example, the hint (a) in principle "Extraction" suggests that service be directed to the customer location. This suggestion can be used with characteristics A and B. In addition, the hint (c) in principle "Extraction" suggests that the service operation be changed to self-service, which can be used with characteristic $\mathrm{C}$.

The repetition of principles in each service approach shows a new concept of priority for implementing principles in each approach. Therefore, in each service approach, the principles were calculated to show the most inventive principles that should always be considered to improve any SRA. Table 7 shows the repetition of principles in each service approach.

\section{Empirical Study}

Grouping of the TRIZ 40 principles with the SRA in this paper will help the designer to efficiently predict the most suitable solution for the contradiction in the current services. Typically, the TRIZ framework suggests that the designer starts with narrowing down to identify the specific problem, then going to the general problem through discovering the contradiction which needs to be resolved, then generating the solution through looking at general solutions provided by the 40 principles, and finally applying those general solutions to the particular problem in order to be closer to the ultimate ideal result. The authors used the TRIZ framework as it is focusing on the stage of generating solutions.

Grouping the 40 principles has been done in Tables 2,3,4,5\& 6 and gives the designer more control in searching for a corresponding principle to be applied for a specific problem. To do that, the designer should know what service redesign approach he/she needs. According to the TRIZ framework, the process of using the proposed tables can be implicated in the following steps:

1- The designer should analyse the problem and identify why it exists and what is the contradiction that caused the problem.

2- Understanding the solution to the contradiction will help the designer to think of the closest service redesign approach in order to solve this problem.

3- After the service approach has been determined, the designer can take into consideration the priority principles in a particular service approach (Table 7).

4- If those principles do not help to predict the solution, the designer needs to look at each characteristic of a particular service approach, which has been determined in step 3. As soon as the designer finds the best characteristic that may lead to generating a solution, he/she can refer to a set of principles that can be used according to Tables 2 to 6 .

5- If step 4 does not help to predict the solution, then the designer may scan the rest of the 40 principles.

Before the designer reaches the worst scenario, step 5, preceding steps will give the designer the opportunity to shortcut the process of scanning the principles. Step 2 and 3 will scope the principles for the designer in the beginning. Then if it does not help, the designer can look at more principles, but not all of them, only the principles related to the service approach - step 4.

To verify the viability of the proposed grouping, the researchers use a case study that was conducted by Chen et al. (2012) in Taiwan. The case study was conducted for improving service system effectiveness in hospitals that provide healthcare for senior citizens in their homes. This service is known as ageing-in-place. Their model was based on the TRIZ contradiction matrix. The problem of the case study was to improve service automation and equipment maintenance, as well as to minimize cost. They analysed the problem according to finding the contradiction between parameters - Engineering Contradictions (EC). Because EC analysis basically needs to find the contradiction between parameters in order to be able to use TRIZ matrix, this study is not focusing on finding solutions for EC. However, analysing problems that are based on EC can still be solved by Physical Contradiction (PC). In fact, every engineering contradiction has one or more PC (San, 2009).

$\mathrm{PC}$ analysis focuses on finding the controlling factor in the EC. For example, in order a table carry many things on it, the surface of the table needs to be large, but this may make the table heavy. The contradiction here is between width and weight parameters. In order to convert EC to PC, a designer needs to find the controlling factor, which is thickness in this case. Therefore, the PC statement will be thin to reduce weight and thick to provide strength. The PC has different strategies in order to solve this type of contradiction such as separation in space, time, upon condition and system level, satisfaction, and bypass. All these strategies involved the grouping 
of some principles, but within a technical problem context. Therefore, while this study used the PC analysis, it used 40 IPs grouping with SRA in order to solve problems in service context.

According to Chen et al. (2012), the EC has two problem statements. The first problem statement was that service automation should be established to quickly enhance meeting senior citizens' needs, but will increase service system cost. The second problem statement was that equipment maintenance should be established to enhance service automation, but this will also increase the service system cost. Actually, establishing equipment for service automation will lead to increase the cost of equipment maintenance. Therefore, the controlling factor in this contradiction is the equipment that assists in automating the service. This means that the designer of the service needs to redesign the service in order to improve the automated service operation by minimizing the equipment. The best approach to redesign the service is self-service approach. This approach refers to enabling the customers (senior citizens) to play a role in performing services (Berry et al., 2000). According to Table 2, the characteristic (D) refers to improving the service automation operation using existing technology. This characteristic includes some inventive principles that could help the designer to generate different solutions for this type of problem.

In a comparison between Chen et al. (2012) and this study, the corresponding principles used to solve this problem contain a few principles that demonstrate a match between the two methods as shown in Table 8 . However, according to Chen et al. (2012) the principle "\#15: Dynamization" got the highest rank in terms of generating the optimal innovative solutions. This principle also can be found in the set of principles grouped under characteristic (D) - see Table 2. Others principles grouped under characteristic (D) can be interpreted to get the same or maybe different solutions. In fact, the principles can be interpreted in different perspectives from one designer to another because the intangibility characteristic is distinct in a service product in contrast to a physical one. Therefore, implementing inventive principles in the service context depends in the first place upon the designer's experience and how he/she uses the principles as a means to solve a problem.

Table 8. Comparison of the two problem solving methods

\begin{tabular}{lll}
\hline & Chen et al. (2012) & The current study \\
\hline Corresponding Principles & $1,15,19,23,28,32$ & $2,7,13,15,17,21,24,25,35$. \\
Service sector & Only for health sector & Different service sectors \\
Contradiction Type & Engineering Contradiction & Physical Contradiction \\
Interpretation & $\begin{array}{l}\text { According to general TRIZ According to TRIZ interpretation in } \\
\text { interpretation in technical context }\end{array}$ & \begin{tabular}{l} 
service context. \\
\hline
\end{tabular} \\
\hline
\end{tabular}

Interpreting the TRIZ principles in service context is more feasible than interpreting based on TRIZ in a technical context. Chen et al proposed the use of online media for monitoring and providing consultation within the residences of senior citizens after the application of principle "\#15: Dynamization" to solve the case study problem. According to the 40 IPs grouping results in this study, this solution can be obtained by using principle "\#13: Inversion", which clearly indicates that the service should be performed in an opposite way (N. Gazem et al., 2014). Thus, instead of a patient going to a hospital for a medical checkup, the patient can get the medical treatment from home via networked video equipment. In addition, Chen et al proposed to outsource equipment maintenance by equipment suppliers after they applied principle "\#1: Segmentation". This solution can be obtained clearly if they use principle "\#24: Intermediary". The hint (e) in principle "intermediary" states that "organizations can outsource non-core functions or process so that they can focus on more valuable functions", (Gazem et al., 2014).

\section{Conclusion}

The theory of inventive problem solving (TRIZ) has been getting attention from many researches in terms of using it in a service context. Most of these researches have been focused on the 40 inventive principles because this tool is commonly used for solving contradiction problems. This research enhanced our previous work for grouping 40 IPs according of different types of redesign service approaches. The grouping process in this study basically depended on a new interpretation of the principles from the service prospective. Hints that developed with each principle have been used as mean in the process of mapping between 40 IPs and SRA characteristics. The new grouping enhanced the previous results by adding new principles into or eliminating the weak coloration principles within a particular SRA characteristic. This study showed that various principles could be 
used in different approaches to redesigning services. Furthermore, some principles can be used repeatedly in a particular service approach. The repetition of principles in each service approach illustrated the most inventive principles that should always be considered to improve any of the service approaches. The feasibility and advantages of using the proposed grouping tables have been demonstrated by comparison of the results of this research with another study for the same case study of an ageing-in-place service agency that provides homecare services in the homes of senior citizens in Taiwan. The comparison result showed that using the grouping tables provide more corresponding inventive principles than those provided by applying TRIZ matrix. This is because the grouping of the 40 principles was dependent on a comprehensive understanding of each principle from the service aspect. It also showed that grouping tables are applicable for solving problems for different service sectors. In addition, although this research as well as the other study by Chen et al. (2012), agreed on the case study solutions, our study was clearer in terms of interpretation of principles as it was based on new interpretative principles for the service context.

Future work will involve the construction of a design model for systematic innovation solving problem using grouping results to utilize 40 inventive principles in the service sector. Thus, the designer of the service can predict the solutions for the services efficiently and effectively by focusing on more appropriate principles that can be applied to a given problem.

\section{Acknowledgments}

I would like to thank the Ministry of Higher Education and Scientific Research of Yemen for the financial support my studying in Malaysia.

\section{References}

Altshuller, G., Shulyak, L., \& Rodman, S. (2005). 40 Principles Extended Edition: TRIZ Keys to Technical Innovation (1st ed.). Worcester, United States: Technical Innovation Center, INC.

Chai, K. H., Zhang, J., \& Tan, K.-C. (2005). A TRIZ-Based Method for New Service Design. Journal of Service Research, 8(1), 48-66. http://dx.doi.org/10.1177/1094670505276683

Chen, C. -K., Shie, A. -J., Wang, K. -M., \& Yu, C.-H. (2012). An Ageing-in-Place Service Innovation Model by Using TRIZ Methodology. Human Factors and Ergonomics in Manufacturing \& Service Industries, n/a-n/a. $\mathrm{http}: / / \mathrm{dx}$.doi.org/10.1002/hfm.20536

Cong, H., \& Tong, L. H. (2008). Grouping of TRIZ Inventive Principles to facilitate automatic patent classification. Expert Systems with Applications, 34(1), 788-795. http://dx.doi.org/10.1016/j.eswa.2006. 10.015

Dourson, S. (2004). The 40 Inventive Principles of TRIZ Applied to Finance. The TRIZ Journal, October.

Filippi, S., Motyl, B., \& Ciappina, F. M. (2011). Classifying TRIZ methods to speed up their adoption and the ROI for SMEs. Procedia Engineering, 9(0), 172-182. http://dx.doi.org/10.1016/j.proeng.2011.03.110

Fox, M. (2008). da Vinci and the 40 Answers (1st ed.). Austin, Texas: Wizard Academy Press.

Gazem, N., \& Rahman, A. A. (2014). Interpretation of TRIZ Principles in Service Context. Asian Social Science, 10(13), 108-130. http://dx.doi.org/10.5539/ass.v10n13p108

Gazem, N. A. J., \& Rahman, A. A. (2013). TRIZ Principles in Redesign Service Approaches. Advances in information Sciences and Service Sciences, 5(11), 273-282.

Hsia, T.-C., \& Pu, L.-B. (2013). Using TRIZ to Improve Maintenance and Repair Services at Jung-xian Auto Repair. Advances in information Sciences and Service Sciences, 5(9), 409-419. http://dx.doi.org/10.4156/ AISS.vol5.issue 9.49

Kim, S., \& Park, Y. (2012). A TRIZ-based Approach to Generation of Service-supporting Product Concepts. World Academy of Science, Engineering and Technology, 62(111), 574-574.

Kuo, D. C., Chi, C., \& Yeh, H. (2013). A Proposed Methodology and its Implications for Industrial-oriented Service Innovation. International Journal of Advancements in Computing Technology, 5(4), 899-906. http://dx.doi.org/10.4156/ijact.vol5.issue4.108

Berry, L., \& Lampo, S. K. (2000). Teaching an Old Service New Tricks. Journal of Service Research, 2(3), 265-275. http://dx.doi.org/10.1177/109467050023004

Lin, C. -S., \& Su, C. -T. (2007). An Innovative Way to Create New Services: Applying the TRIZ Methodology. Journal of the Chinese Institute of Industrial Engineers, 24(2), 142-152. http://dx.doi.org/10.1080/ 


\section{9}

Mann, D. (2007). Hands on Systematic Innovation: For Business and Management. UK: Edward Gaskell Publishers.

Mann, D., \& Domb, E. (1999). 40 Inventive (Business) Principles with Examples. The TRIZ Journal, September.

Metters, R., Pullman, M., \& King-Metters, K. (2003). Successful Service Operations Management. Australia: South-Western College Pub.

Regazzoni, D., Pezzotta, G., Persico, S., Cavalieri, S., \& Rizzi, C. (2012). Integration of TRIZ Problem Solving Tools in a Product-Service Engineering Process. In Y. Shimomura \& K. Kimita (Eds.), The Philosopher's Stone for Sustainability (pp. 399-404). Springer Berlin Heidelberg.

Retseptor, G. (2003). 40 Inventive Principles in Quality Management. The TRIZ Journal, March.

Ruchti, B., \& Livotov, P. (2001). TRIZ-based Innovation Principles and a Process for Problem Solving in Business and Management. TRIZ Journal, December.

San, Y. T. (2009). TRIZ - Systematic Innovation in Manufacturing. Malaysia: Firstfruits Sdn Bhd.

Xie, J., Tang, X., \& Shao, Y. (2012). Research on Integrated Innovation Design Method of TRIZ and QFD Based on the Consumer Demand Decision. International Journal of Information Processing and Management, 3(2), 14-24. http://dx.doi.org/10.4156/ijipm.vol3.issue2.3

Zhang, J., Chai, K. -H., \& Tan, K. -C. (2003). 40 Inventive Principles with Applications in Service Operations Management. The TRIZ Journal, December.

Zhang, J., Chai, K.-H., \& Tan, K.-C. (2005). Applying TRIZ to service conceptual design: an exploratory study. Creativity and Innovation Management, 14(1), 34-42. http://dx.doi.org/10.1111/j.1467-8691.2005.00323.x

\section{Copyrights}

Copyright for this article is retained by the author(s), with first publication rights granted to the journal.

This is an open-access article distributed under the terms and conditions of the Creative Commons Attribution license (http://creativecommons.org/licenses/by/3.0/). 